\title{
Correction to: Simultaneous Separation of Water and Fat Soluble Vitamins by Selective Comprehensive HILIC $\times$ RPLC (High Resolution Sampling) and Active Solvent Modulation
}

\author{
Stefanie Bäurer ${ }^{1} \cdot$ Wenkai Guo $^{1} \cdot$ Stefan Polnick ${ }^{1} \cdot$ Michael Lämmerhofer $^{1} \mathbb{C}$
}

Published online: 3 August 2020

(c) Springer-Verlag GmbH Germany, part of Springer Nature 2020

\section{Correction to: Chromatographia (2019) 82:167-180 \\ https://doi.org/10.1007/s10337-018-3615-0}

In this article, we depicted the structure of the investigated fat-and water-soluble vitamins in Fig. 2. Unfortunately, the published structure in Fig. 2 was vitamin $\mathrm{K}_{3}$ (Menadione) instead of vitamin $\mathrm{K}_{1}$ (Phytomenadione) ( $\log P=9.7$, calculated with Marvin Sketch) which was actually used in the presented experiments.

Additionally, we want to clarify the final buffer concentration of the ${ }^{1} \mathrm{D}$ gradient method which was $15 \mathrm{mM}$ ammonium acetate ( $\mathrm{pH}$ adjusted to 4.5 ) as correctly stated in the respective Figure captions and the ${ }^{2} \mathrm{D}$ conditions used for the separations depicted in Fig. 10 (conditions as described in the Materials and Methods part are correct): Mobile phases: A: $\mathrm{H}_{2} \mathrm{O}, 0.1 \% \mathrm{FA}, \mathrm{B}: \mathrm{ACN}, 0.1 \% \mathrm{FA}$, isocratic separation at $80 \% \mathrm{~B}$ after direct transfer, focusing (5\% B), and focusing (5\% B) with ASM, respectively. The corresponding text is still correct.

Publisher's Note Springer Nature remains neutral with regard to jurisdictional claims in published maps and institutional affiliations.
The original article can be found online at https://doi.org/10.1007/ s10337-018-3615-0.

Michael Lämmerhofer

michael.laemmerhofer@uni-tuebingen.de

Institute of Pharmaceutical Sciences, Pharmaceutical (Bio-) Analysis, University of Tübingen, Auf der Morgenstelle 8, 72076 Tübingen, Germany 